\title{
Kiat Jitu Menembus Jurnal International Bereputasi, Optimalisasi Mendeley \& Grammarly dalam Pengabdian Webinar Teknik Informatika UISU
}

\author{
Nurul Khairina ${ }^{1)} \mid$ Adidtya Perdana $^{2)} \mid$ Muhammad Khoiruddin Harahap ${ }^{3)} \mid$ Mhd. Zulfansyuri \\ Siambaton ${ }^{4)}$ \\ ${ }^{1)}$ Universitas Medan Area $\mid{ }^{2)}$ Universitas Harapan Medan | ${ }^{3)}$ Politeknik Ganesha Medan | \\ ${ }^{4)}$ Universitas Islam Sumatera Utara \\ nurulkhairina27@gmail.com | adid.dana@gmail.com | choir.harahap@yahoo.com | \\ zulfansyuri@ft.uisu.ac.id
}

\begin{abstract}
Abstrak: Kehidupan akademik tidak dapat lepas dari kegiatan publikasi artikel ilmiah. Meningkatkan kemampuan dan wawasan dosen serta mahasiswa dalam menulis artikel ilmiah menjadi motivasi tersendiri dalam kegiatan pengabdian masyarakat ini. Tuntutan berupa publikasi artikel ilmiah dalam ranah nasional mapupun international bagi dosen seperti pelaporan beban kerja dosen, persyaratan kepangkatan dosen, persyaratan melanjutkan studi (dari S1 ke S2 atau dari S2 ke S3), persyaratan menyelesaikan studi (salah satu syarat dalam menyelesaikan studi S2 dan S3), persyaratan mengambil ijazah bagi mahasiswa S1, persyaratan wisuda, serta luaran penelitian maupun luaran pengabdian selalu tetap membutuhkan kemampuan dalam menulis artikel ilmiah. Maka dari itu tim pengabdiaan yang beranggotakan penulis, dkk melakukan kegiatan pengabdian masyarakat dengan tema kiat jitu menembus jurnal internasional bereputasi, optimalisasi mendeley, dan grammarly yang dilaksanakan dalam bentuk webinar dan diselengarakan oleh program studi teknik informatika UISU. Peserta pada kegiatan ini tidak hanya berasal dari kalangan mahasiswa dan akademisi saja melainkan dari kalangan umum, dan berasal dari dalam dan luar kota Medan, bahkan ada dari luar Provinsi. Kegiatan pengabdian ini dilaksanakan secara daring karena masih dalam masa pandemic, walaupun terbatas dengan tempat dan waktu, namun tim pengabdian dan peserta sangat antusias dalam mengikuti acara webinar. Hal ini menunjukkan bahwa minat dan kebutuhan dalam menulis publikasi ilmiah sangat besar dan kebutuhan pada pembimbingan penulisan karya ilmiah juga sangat besar.
\end{abstract}

Kata Kunci: kiat jitu; jurnal international bereputasi; mendeley; grammarly; uisu

\section{Pendahuluan}

Tridhama perguruan tinggi menjadi salah satu komponen penilaian kinerja dosen. Dalam memenuhi komponen penelitian, dosen dapat mempublikasikan artikel ilmiah secara berkala pada taraf nasional dan international. Tidak terlalu jauh berbeda dengan Tridharma Dosen, mahasiswa juga membutuhkan publikasi jurnal untuk menyelesaikan studi jenjang sarjana, magister dan doktoral.

Menurut Kemenristekdikti, mahasiswa studi doktoral harus melakukan publikasi pada taraf International untuk menyelesaikan studinya, begitu juga dengan promosi menjadi Profesor dan evaluasi kinerja Profesor. Tunjangan Profesor dapat diberhentikan apabila Profesor tidak melakukan publikasi pada taraf International (Sutanto, 2020). Menulis artikel ilmiah dalam taraf International dibutuhkan keseriusan dan pemahaman yang mendalam. Oleh karena itu diperlukan skill yang terarah agar mampu menghasilkan suatu karya ilmiah yang baik. 
Dalam menulis artikel kita dapat mempublikasikannya pada jurnal nasional maupun internasional. Jurnal yang bereputasi baik nasional maupun internasional memiliki syarat, telah terakreditasi oleh Kementerian Riset, Teknologi dan Pendidikan Tinggi melalui SINTA untuk jurnal nasional dan telah terindex oleh peng-index bereputasi seperti Scopus, WoS, Thomson reuters, dll untuk jurnal internasional (Firmansyah et al., 2020).

Selain itu, kemampuan yang diperlukan dalam mempublikasikan artikel ilmiah adalah kemampuan mengatur referensi dengan baik. Referensi merupakan suatu hal paling penting dalam penulisan suatu artikel ilmiah (Astuty et al., 2021). Tanpa referensi yang baik maka indikasi terjadinya plagiat akan semakin besar. Sehingga diperlukan suatu aplikasi yang dapat membantu dalam mengatur referensi, aplikasi tersebut adalah Mendeley (Pramiastuti et al., 2020).

Mendeley merupakan suatu aplikasi reference manager dimana didalam aplikasi ini digunakan untuk mengumpulkan, menyusun, mensortir, serta menyimpan referensi yang digunakan (Utami et al., 2020). Selain itu Mendeley juga mampu membantu dalam penggunaan sitasi secara cepat kedalam tulisan yang dikerjakan. Serta dapat membantu dalam manajemen daftar pustaka (Perdana, 2020).

Kemampuan selanjutnya yang perlu dimiliki jika ingin mempublikasikan artikel pada jurnal internasional adalah kemampuan bahasa inggris yang baik (Setiawan et al., 2020). Dalam menulis artikel internasional diperlukan penulisan dalam bahasa inggris yang baik dan benar. Untuk mendapatkan kemampuan tersebut diperlukan waktu yang cukup lama untuk mempelajarinya. Sedangkan kebanyakan dari masyarakat sangat minim dalam kemampuan berbahasa inggris dikarenakan bahasa inggris bukan bahasa ibu (mother tongue) (Zupita et al., 2020). Maka kita dapat memanfaatkan aplikasi yang sudah ada untuk membantu dalam membuat tulisan dalam bahasa inggris dengan baik dan benar, aplikasi tersebut adalah Grammarly dan dibantu dengan Google Translate (Sitoresmi \& Sumardiono, 2020).

Dengan adanya fenomena tersebut, tim pengabdian berinisiatif melakukan kegiatan pengabdian masyarakat dengan memberikan kiat jitu dalam menulis artikel ilmiah yang dapat dipublikasikan pada taraf international bereputasi. Dengan adanya kegiatan pengabdian ini, tim pengabdian berharap bahwa peserta webinar yang terdiri dari dosen dan mahasiswa dapat termotivasi dan terbantu dalam menulis dan mempublikasikan karya ilmiahnya pada taraf international. Adapun kegiatan pengabdian masyarakat terdahulu yang berkaitan dengan pengabdian ini, salah satunya adalah kegiatan pengabdian yang pernah dilaksanakan oleh penulis dkk, yang melaksanakan kegiatan pengabdian masyarakat tentang Academic Writing pada acara Webinar IKAPASTI-USU (Khairina et al., 2020).

\section{Realisasi Kegiatan}

Kegiatan pengabdian dilakukan secara daring melalui zoom meeting dan channel youtube yang disediakan oleh Teknik Informatika Universitas Islam Sumatera Utara (UISU). Kegiatan pengabdian ini dilaksanakan pada hari Sabtu tanggal 5 Desember tahun 2020 dari pukul 09.00 WIB sd 16.00 WIB. Kegiatan ini dibuka oleh Ir. Abdul Haris Nasution, MT selaku Dekan Fakultas Teknik dan Mhd. Zulfansyuri Siambaton, ST, M.Kom selaku Ketua Program Studi Teknik Informatika. Kegiatan pengabdian dibawakan oleh dosen Teknik Informatika yang dibagi menjadi tiga sesi seperti rincian pada Tabel 1 berikut :

Tabel 1. Moderator, Narasumber dan Materi Webinar

\begin{tabular}{|c|l|l|l|}
\hline No & \multicolumn{1}{|c|}{ Moderator } & \multicolumn{1}{c|}{ Narasumber } & \multicolumn{1}{c|}{ Materi } \\
\hline 1 & Khairuddin Nasution, ST, M.Kom & $\begin{array}{l}\text { Muhammad Khoiruddin } \\
\text { Harahap, ST, M.Kom }\end{array}$ & $\begin{array}{l}\text { Kiat menembus jurnal } \\
\text { international bereputasi }\end{array}$ \\
\hline 2 & Oris Krianto Sulaiman, ST, M.Kom & Adidtya Perdana, ST, M.Kom & Optimalisasi Mendeley \\
\hline 3 & Tasliyah Haramaini, S.Si, M.Kom & Nurul Khairina, M.Kom & Optimalisasi Grammarly \\
\hline
\end{tabular}


Adapun materi yang disampaikan oleh tim pengabdian adalah sebagai berikut:

a. Materi pertama yang disampaikan adalah tentang Kiat menembus jurnal international bereputasi :
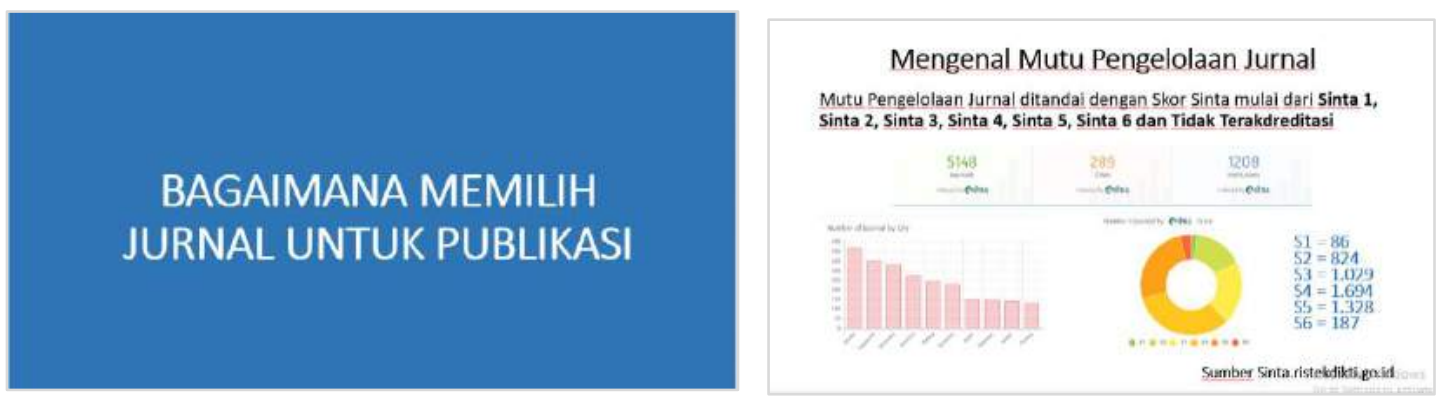

Gambar 1. Tips Memilih Jurnal dan Mengenal Pengelolaan Jurnal

Selanjutnya tim menjelaskan tentang poin-poin penting dalam penelitian serta struktur umum karya ilmiah seperti dapat dilihat pada Gambar 2 dan Gambar 3 :
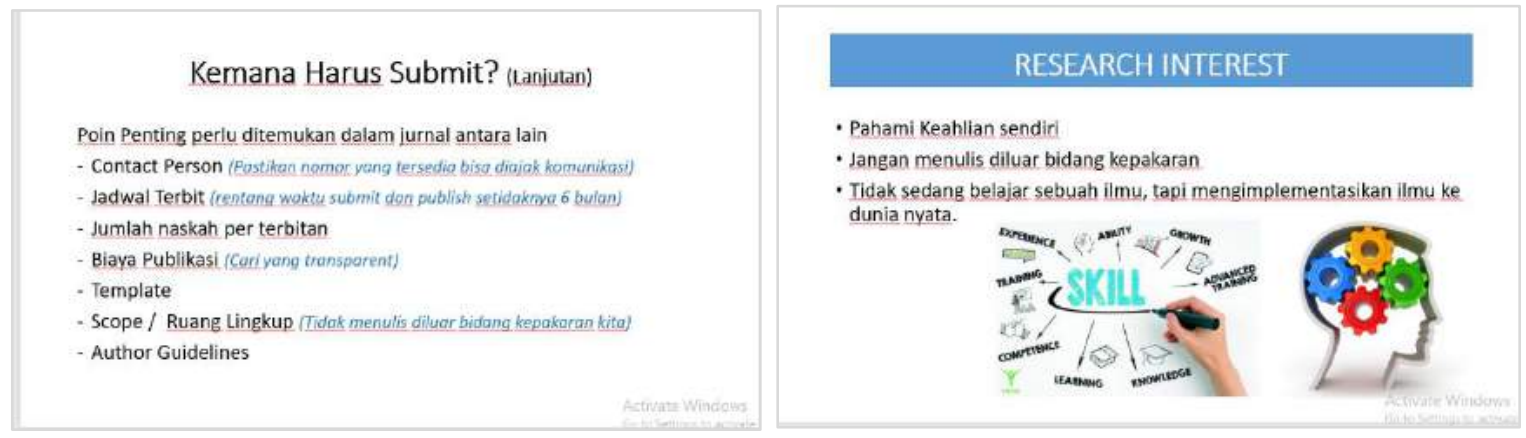

Gambar 2. Poin-Poin Penting dalam Penelitian

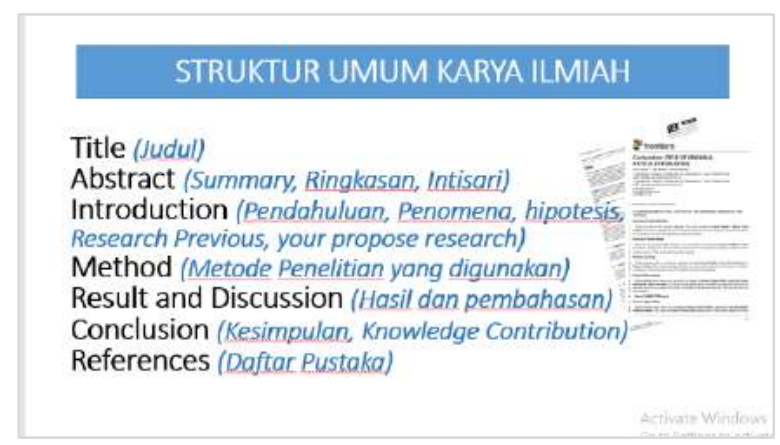

Gambar 3. Struktur Karya Ilmiah

Selanjutnya tim pengabdian menjelaskan tentang tips dan trik menulis jurnal International bereputasi yang dimulai dari sebuah penelitian yang berawal dari hasil penelitian sebelumnya. Adapun pembahasan pokok tentang tips dan trik menulis jurnal International kususnya bagian pembahasan, kesimpulan, metode, pendahuluan, abstrak, judul serta referensi dapat dilihat pada Gambar 4 : 


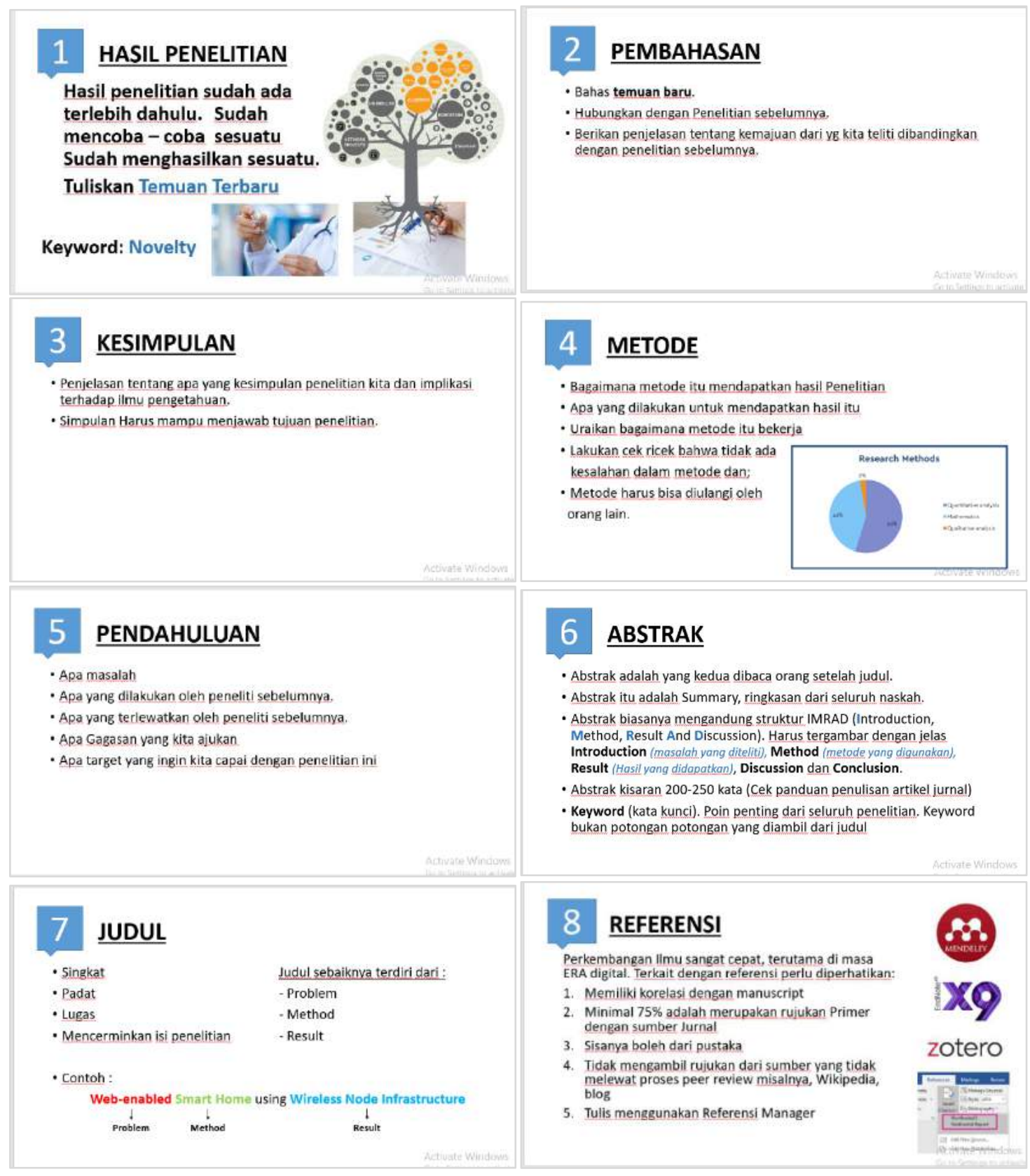

Gambar 4. Trik Menulis Jurnal International Bereputasi

Selanjutnya tim pengabdian menjelaskan trik tambahan untuk meningkatkan kemampuan dalam menulis jurnal Interntional bereputasi, salah satunya dengan melakukan cek similiarity dan diskusi dengan pakar seperti yang dapat dilihat pada Gambar 5 : 


\section{ACKNOWLEDGMENT}

Menyampaikan apresiasi dan terima kasih kepada semua pihak yang berkontribusi

- Penyandang dana (jika ada)

- Singkat dan Padat

- Lugas

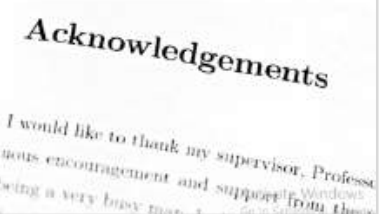

\section{CEK SIMILARITY}

Setiap pengelola jurnal memiliki kebijakan tingkat similarity masing masing. Secara umum tingkat similarity berdasarkan bidang ilmu adalah:

Bidang Ilmu Eksakta Maksimal 20\%

Bidang IImu Non Eksakta 30\%

Ada beberapa yang lebih dari itu, silahkan cek di panduan penulisan jurnal yang akan dituju turnitin

Crossref Simtarity Choch UrKunD Plagiarism

\section{DISKUSIKAN DENGAN PAKAR}

Jangan sungkan untuk meminta review para pakar yang kompeten dalam masalah itu.

Mintalah saran dan kritik yang membangun

Kontribusi pihak luar akan menambah khasanah penelitian anda.

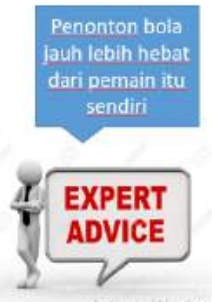

Gambar 5. Trik Menulis Jurnal International Bereputasi

b. Materi kedua yang disampaikan adalah tentang Optimalisasi Mendeley :

\section{REFERENSI}

\section{Mengapa Penting?}

- Referensi adalah segala bentuk teori yang digunakan dalam menunjang dan mempertegas ide, gagasan, teori atau argumentasi yang disampaikan dalam suatu tulisan karya ilmiah.

- Referensi = Rujukan

- Merujuk pada suatu sumber

- Menguatkan teori dan argument pada karya ilmiah.

- Menghindari plagiat.

- Sebagai penghargaan pada karya orang lain.

- Memberi informasi kepada pembaca.

Gambar 6. Teori Referensi

Selanjutnya slide kedua menjelaskan sumber-sumber untuk referensi dan syarat suatu referensi yang layak digunakan yang dapat dilihat pada pada Gambar 7 : 


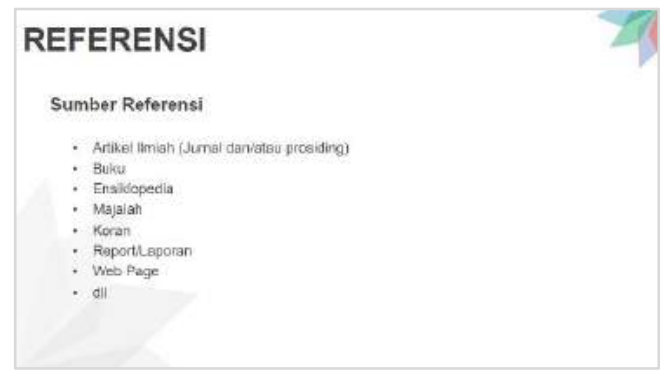

\section{REFERENSI}

Syarat

Primer, Hasil perellitian yang dipublikasikan balk datam Juma bereputasi, Jumai tâk

bereputsal, proceeding conference, maupun bukil

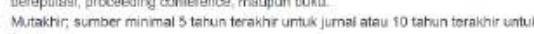

- Felevari, berkatian dengan karra inriah yang ditovat.

Gambar 7. Sumber-Sumber dan Syarat Referensi

Slide selanjutnya menjelaskan mengenai sitasi dan cara penggunaan yang baik dan benar serta style apa saja yang dapat digunakan yang tersaji pada Gambar 8 :

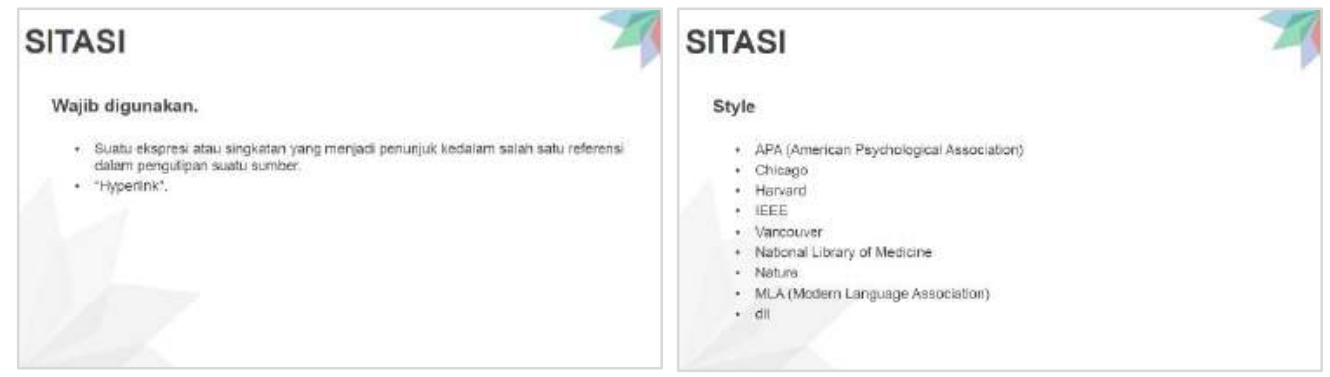

Gambar 8. Sitasi dan Style Sitasi

Selanjutnya tim menjelaskan tips-tips cara mengutip dari sumber yang tersaji pada Gambar 9:

\section{TIPS}

Teknik Mengutip Sumber

- Kutipan Langsung

- Paraprashing

- Summarizing

Gambar 9. Tips Mengutip Sumber Referensi

c. Setelah menjelaskan sedikit materi teoritis maka tim langsung memberikan materi secara praktek dalam melakukan pengunduhan dan pemasangan aplikasi Mendeley. Hal pertama yang disampaikan adalah bagaimana mendapatkan aplikasi Mendeley yaitu men-download dari situs https://www.mendeley.com/download-desktop-new/ . 
Selanjutnya membuka file Mendeley dan lakukan instalasi.

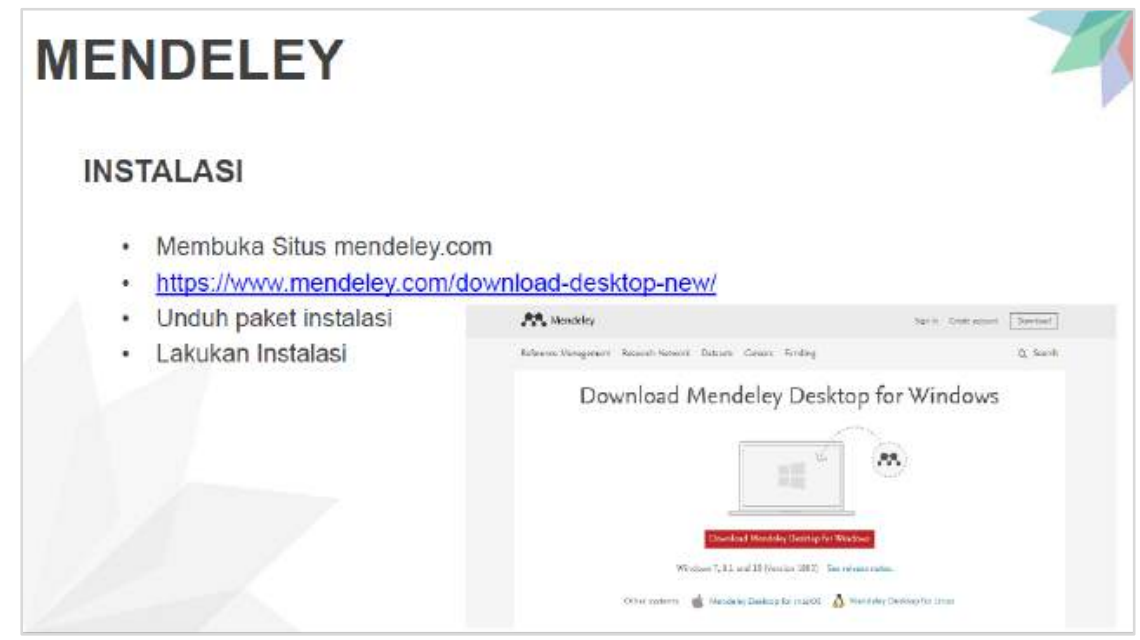

Gambar 10. Pengunduhan dan Instalasi Mendeley

Selanjutnya tim mengarahkan peserta untuk Registrasi Akun Mendeley terlebih dahulu sebelum mulai menggunakan aplikasi ini. Setelah itu lakukan Sign In di aplikasi Mendeley-nya agar bisa digunakan.

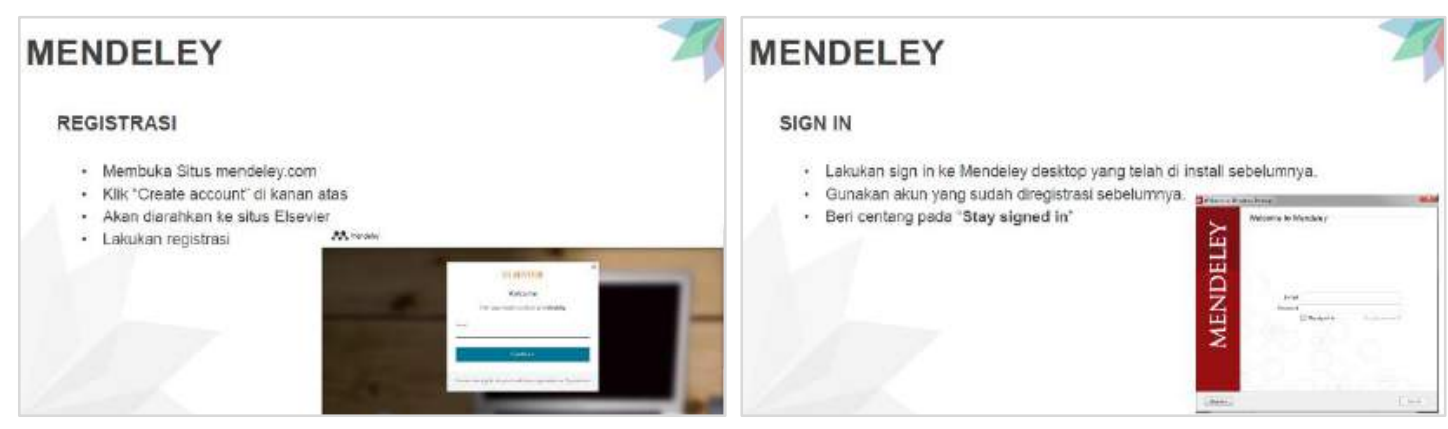

Gambar 11. Registrasi Akun Mendeley dan Sign In

Selanjutnya tim menjelaskan bagaimana menggunakan aplikasi Mendeley ini untuk reference manager pada penulisan karya ilmiah. Pertama tim menjelaskan bagaimana cara menambahkan referensi pada tulisan kita. Kemudian tim menjelaskan bagaimana menambahkan plugin pada Word Processing masing-masing. Kemudian tim menjelaskan bagaimana mengatur style refernsi atau sitasi. Selanjutnya tim menjelaskan bagaimana menambahkan bibliografi kedalam tulisan. Dan menjelaskan beberapa tips dan trik menggunakan mendeley ini. 

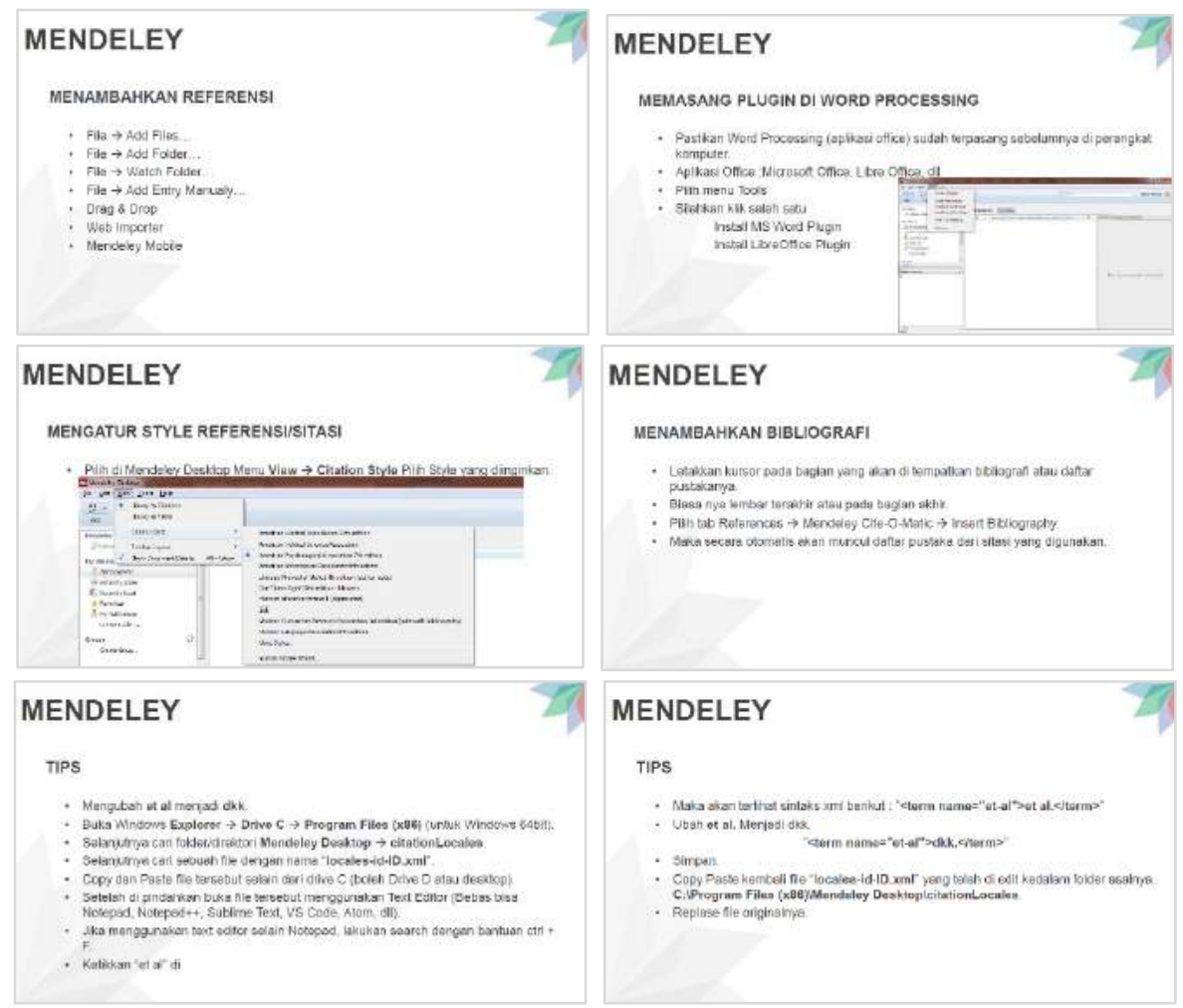

Gambar 12. Cara menambahkan Sitasi dan Bibiliografi sesuai Style

d. Selanjutnya tim menjelaskan bagaimana menerapkan Mendeley ini langsung ke draft karya ilmiah dengan cara mempraktekkan secara langsung.

e. Materi ketiga yang disampaikan adalah pemaparan tentang Optimalisasi Grammarly dalam menulis Karya Ilmiah International. Tahapan dalam melakukan instalasi Grammarly dan membuat akun Grammarly dapat dilihat pada Gambar 13 :

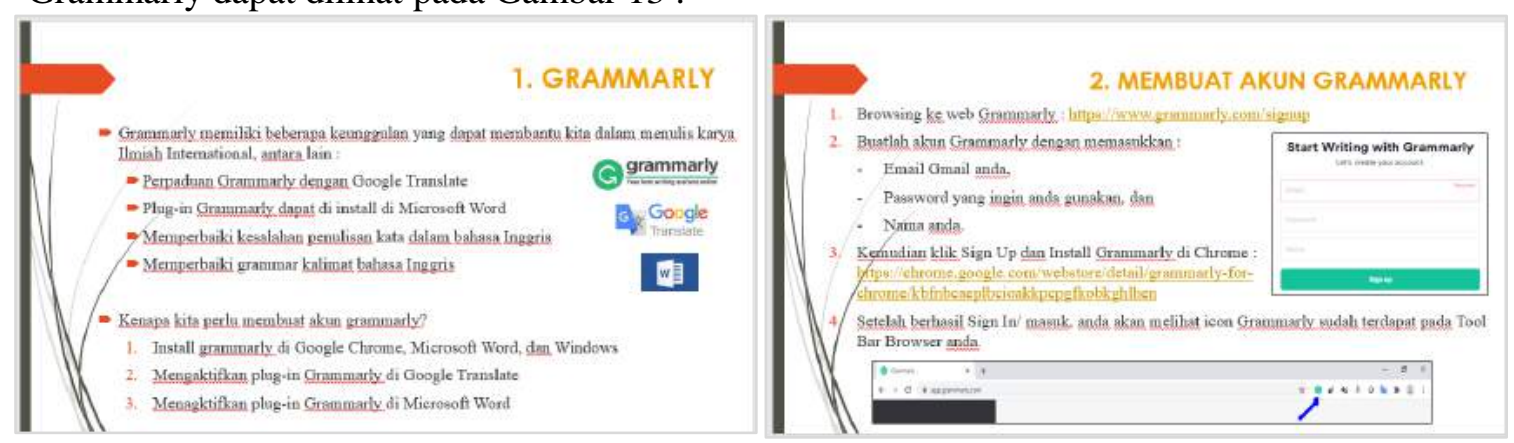

Gambar 13. Instalasi Grammarly dan Membuat Akun Grammarly

Selanjutnya tim pengabdian menjelaskan bagaimana caranya memadukan grammarly dan google translate agar memberikan hasil translate yang optimal, kemudian tim pengabdian juga mempraktekkan bagaimana cara memasang Plug-in Grammarly di MS Word. Materi dapat dilihat pada Gambar 14 : 


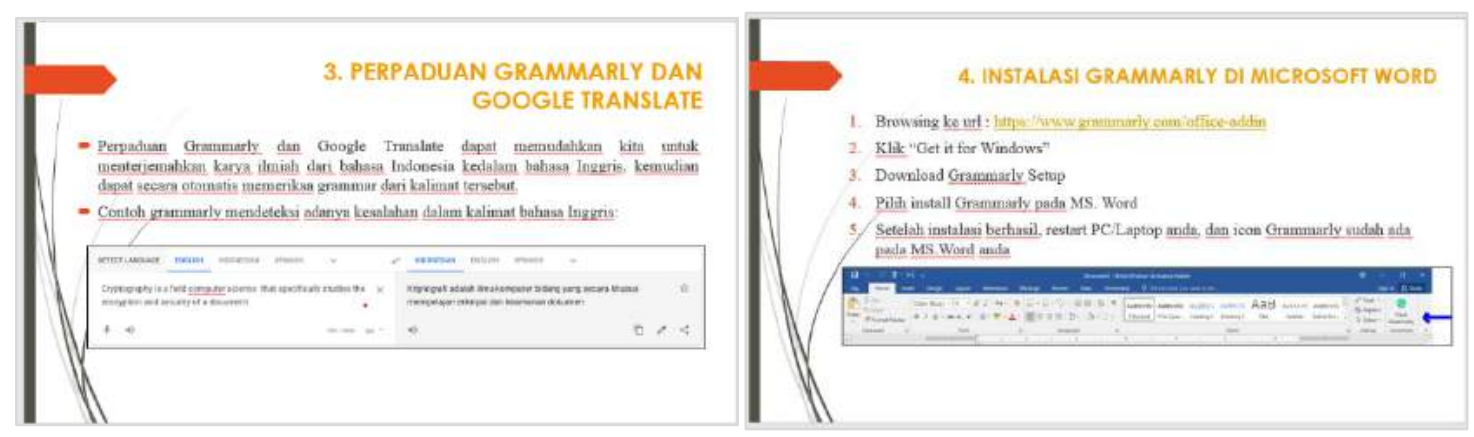

Gambar 14. Perpaduan Grammarly dan Google Translate dan Instalasi Grammarly di MS Word

Langkah terakhir adalah mengoptimalkan grammarly pada karya ilmiah International yang dilakukan dengan Plug-in Grammarly yang sudah diinstall di MS Word. Materi dapat dilihat pada Gambar 15 :
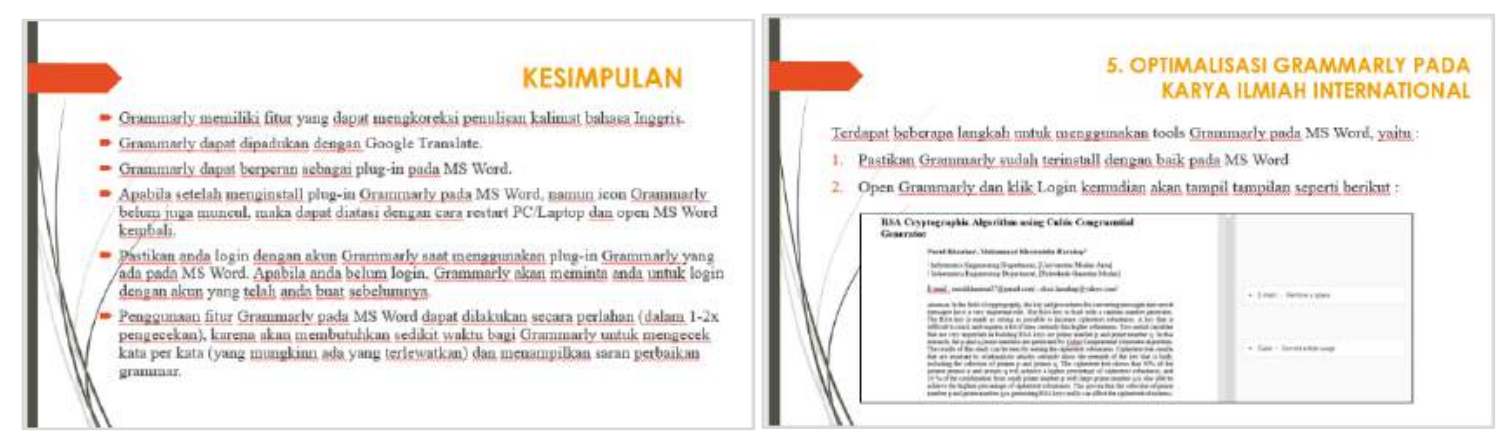

Gambar 15. Optimalisasi Grammarly pada Karya Ilmiah International serta Kesimpulan

Adapun dokumentasi dari kegiatan pengabdian ini adalah seperti yang dapat dilihat pada Gambar 16 : 

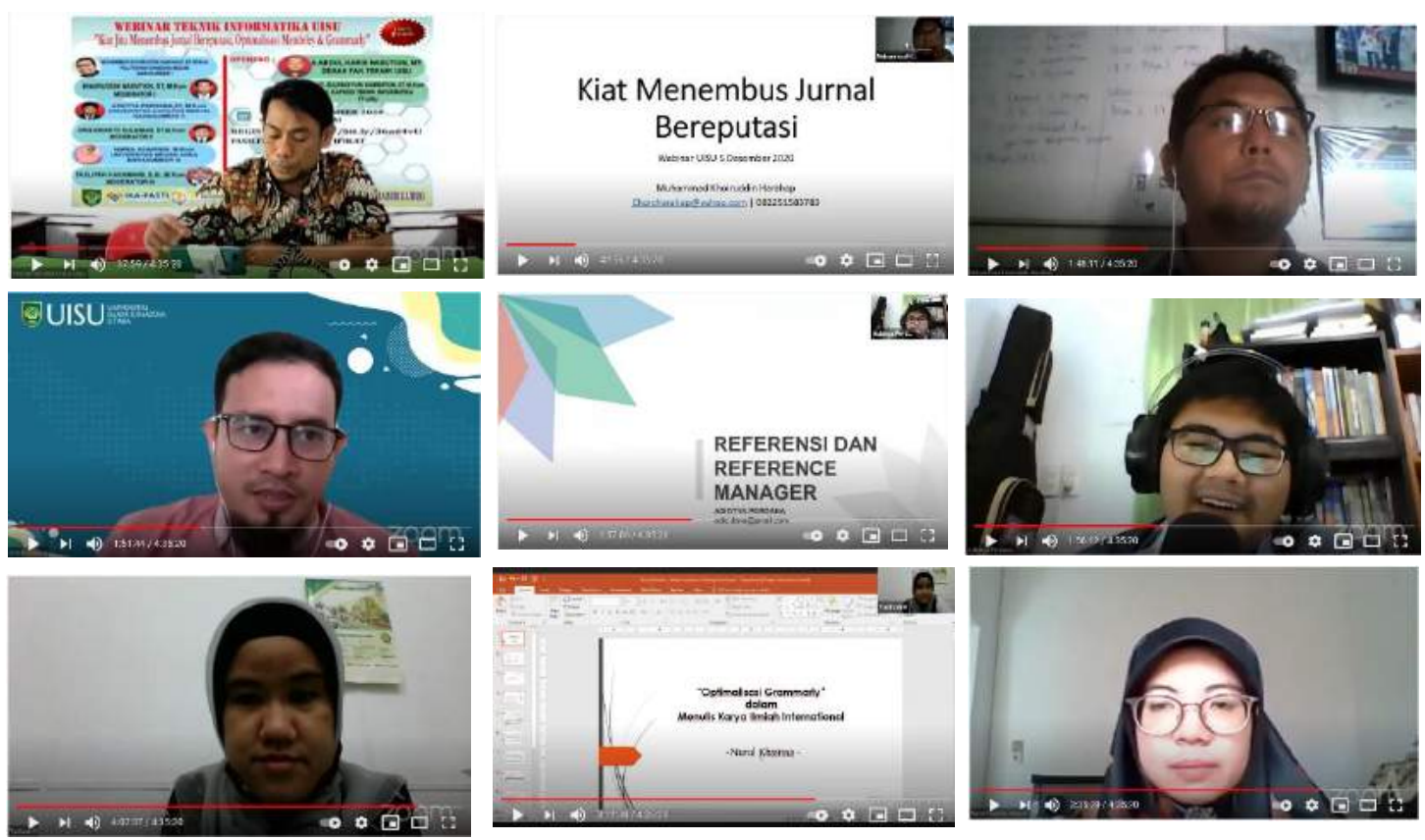

Gambar 16. Dokumentasi Webinar Kiat Jitu Menembus Jurnal Intenantional Bereputasi, Optimalisasi Mendeley dan Grammarly

\begin{abstract}
Hasil
Kegiatan pengabdian masyarakat pada webinar Kiat Jitu Menembus Jurnal International Bereputasi, Optimalisasi Mendeley dan Grammarly ini telah berjalan dengan lancar dan menuai ketertarikan dari para peserta. Narasumber, panitia seminar serta peserta yang terdiri dari kalangan dosen dan mahasiswa yang terlibat dalam kegiatan ini berasal dari perguruan tinggi yang berbeda dari seluruh Indonesia. Kegiatan ini sangat membantu para dosen dan mahasiswa apabila ingin mempublikasikan karya ilmiahnya ke ranah International bereputasi, serta dapat meningkatkan antusiasme dan motivasi para dosen. Hal ini terlihat dari adanya beberapa pertanyaan peserta yang ditujukan kepada masing-masing narasumber, antara lain : bagaimana hasil penelitian apabila tidak sesuai dengan hasil yang diharapkan, apakah penelitian gagal atau berhasil, lalu bagaimana cara merubah style sitasi, style mana yang lebih baik antara APA style dan IEEE style, dan bagaimana perbandingan hasil translate dengan translator manual dan Grammarly. Semua pertanyaan yang ditujukan kepada narasumber dapat menambah wawasan para peserta, agar dosen dan mahasiswa dapat terus berkarya dan menghasilkan publikasi yang berkualitas.
\end{abstract}

\title{
Kesimpulan
}

Kegiatan pengabdian masyarakat melalui webinar Kiat Jitu Menembus Jurnal International Bereputasi, Optimalisasi Mendeley dan Grammarly bertujuan untuk membantu dan memotivasi para dosen dan mahasiswa untuk berkarya di ranah International. Kegiatan pengabdian ini bukan hanya bermanfaat bagi para dosen, tetapi juga dapat bermanfaat bagi para mahasiswa yang sedang menyelesaikan studinya, karena publikasi ilmiah menjadi persyaratan yang penting untuk menyelesaikan studi dan mengambil ijazah.

\section{Ucapan Terimakasih}

Ucapan terimakasih sebesar-besarnya kami sampaikan kepada seluruh jajaran pimpinan Fakultas Teknik dan Program Studi Teknik Informatika. Atas waktu dan tempat yang diberikan kepada kami, kegiatan pengabdian ini dapat terlaksana dengan baik. 


\section{$\underline{\text { Daftar Pustaka }}$}

Astuty, E., Asmin, E., \& Sukmawaty, E. (2021). Diskusi Online: Manajemen Referensi (Aplikasi Mendeley) Dalam Penulisan Karya Ilmiah. Jurnal Pengabdian Masyarakat Khatulistiwa, 4(1), 31-35. https://doi.org/10.31932/jpmk.v4i1.866

Firmansyah, A., Qadri, R. A., \& Arham, A. (2020). Pelatihan melalui Web Seminar terkait Publikasi Artikel untuk Menembus Jurnal Sinta 2 dan Scopus. Abdimas: Jurnal Pengabdian Masyarakat Universitas Merdeka Malang, 5(2). https://doi.org/10.26905/abdimas.v5i2.4244

Khairina, N., Perdana, A., Harahap, M. K., \& Siambaton, M. Z. (2020). Academic Writing: Optimalisasi Mendeley, Grammarly dan Google Translate dalam Pengabdian Webinar Series IKAPASTI-USU. Jurnal Prioritas: Jurnal Pengabdian Masyarakat, 02(02), 1-9.

Perdana, F. J. (2020). Pelatihan Membuat Daftar Pustaka Otomatis Dengan Aplikasi Mendeley Desktop Bagi Mahasiswa Dalam Persiapan Penyusunan Tugas Akhir. Dimasejati: Jurnal Pengabdian Kepada Masyarakat, 2(1), 75. https://doi.org/10.24235/dimasejati.v2i1.6652

Pramiastuti, O., Rejeki, D. S., \& Pratiwi, A. (2020). Pengenalan Dan Pelatihan Sitasi Karya Ilmiah Menggunakan Aplikasi Mendeley. Jurnal Abdimas Bhakti Indonesia, 1(1), 24-30. http://ojs.stikesbhamadaslawi.ac.id/index.php/JABI/article/view/178/168

Setiawan, E., Rahman, D. A., \& Kristanto, R. (2020). Pelatihan Keterampilan Menulis dalam Korespondensi Berbahasa Inggris, Menerjemahkan serta Keterampilan Menggunakan Grammarly, Google Translate, dan Google Drive di Sekolah Menengah Kejuruan KSATRYA, Rawasari, Jakarta Pusat. Jurnal Komunitas : Jurnal Pengabdian Kepada Masyarakat, 2(2), 118 126. https://doi.org/10.31334/jks.v2i2.733

Sitoresmi, U., \& Sumardiono. (2020). OPTIMALISASI KETERAMPILAN BERBAHASA INGGRIS MELALUI PEMANFAATAN SOFTWARE PEMBELAJARAN BAHASA BAGI ANGGOTA KARANG TARUNA RT 01 RW 27 KADIPIRO SURAKARTA. Adi Widya: Jurnal Pengabdian Masyarakat, 4(1a), 146-151. http://journal.unnes.ac.id/sju/index.php/edaj

Sutanto, L. (2020). KIAT JITU MENEMBUS JURNAL INTERNASIONAL: TERINDEKS SCOPUS. Gramedia Pustaka Utama.

Utami, P. S., Asmaroini, A. P., Cahyono, H., Pancasila, P., \& Muhammadiyah, U. (2020). Pelatihan Pemanfaatan Program Mendeley Dekstop dalam Pembuatan Citasi Karya Ilmiah bagi Mahasiswa di Kabupaten Ponorogo Perkembangan era revolusi. Jurnal Pengabdian Masyarakat: Darma Bakti Teuku Umar, 2(2), 248-256.

Zupita, N., Fitriani, Y. E., \& Rohayati, Y. (2020). Ti Dalam Pendidikan: Studi Literasi Bahasa Inggris Dalam Membaca Dan Menulis Dikalangan Mahasiswa Era Digital. Seminar Nasional Pendidikan, FKIP UNMA 2020, 236-244. https://prosiding.unma.ac.id/index.php/semnasfkip/article/view/327 